\title{
Medico-Legal Evidence in Rape Cases: Analysis with Special Reference to Sri Lanka
}

\author{
Muthukuda Arachchige Dona Shiroma Jeeva Shirajanie Niriella*
}

\begin{abstract}
Rape incidents against women have increased due to various reasons over the past few years in Sri Lanka. In the recent past, the brutal nature of the rape incidents has escalated along with the subsequent assassination of the rape victims. It is a known fact that the dark figure rate of rape is considerably higher than the reported rape incidents in Sri Lanka. Many reported rape cases are not concluded with conviction and this allows the perpetrators to unjustly enjoy impunity. This thrusts victims into vulnerable situations shrouded in social stigma. Medicolegal evidence plays a vital role in rape cases; perhaps, it may be the best evidence that the prosecution has to prove the case. Furthermore, the medico-legal evidence can be used for the purpose of corroborating the story of the victim. This evidence has immense probative value as the witness is an independent third party who is a professionally qualified expert in the field of forensic medicine and the Law of Evidence in Sri Lanka considers the opinion of expert as direct evidence. The quality and the reliability of medico-legal evidence depends on the medicolegal examination performed on the victim. An efficient medico-legal service is of utmost importance in this regard. In many instances, medico-legal evidence has not been consistent with the story of the victim which have raised concerns regarding the quality of medico-legal evidence and medico-legal services available.
\end{abstract}

Faculty of Law, University of Colombo, Sri Lanka *Corresponding author; email: jeevaniriella@gmail.com
The objective of this paper is to review legislation relating to medico-legal evidence and services in Sri Lanka to improve its quality such that justice is provided to the rape victim through a successful prosecution.

\section{Keywords}

Medico-legal evidence, medico-legal service, offence of rape, Sri Lanka

\section{Introduction}

Committing the offence of rape has been recognized as a social and public health issue. In Sri Lanka it is considered as a gender specific violence, committed by a man against a woman. In addition to the physical injuries, a rape victim has to under go mental trauma (Guidelines for medico-legal care for victims of sexual violence, pp 12-16; Rattan Sing vs. State of Punjab 19794 SCC 719; Jack Straw, 1999 cited in Sanders, 2002, p. 197) associated with social stigma. In a culturally conservative country like Sri Lanka, such an incident would be seriously devastating to mental health, physical wellbeing, self-esteem and adversely damages the social recognition and future aspirations of a woman. In some cases, the woman is ostracized by her own family. Unlike other offences that are categorized under physical offences against the human body, the offence of rape entails both immediate and long-term sexual and reproductive health issues as well.

Bringing the perpetrators before the justice system and punishing them is necessary to provide justice to the rape victim. Often, the 
Muthukuda A D S J S Niriella, 2018, European Journal of Social Sciences (EJSS), vol. 1, no. 1,

victim is the only witness to the crime. From investigation to determination of the verdict, the woman has to recall and repeatedly converse with the officials of the criminal justice system about the painful ordeal she underwent. Due to this, rape victims are often hesitant when cooperating with authorities. Therefore, contradictions occur between the first complaint made to the police and the testimony (evidence) given at the trial in the court by the rape victim. These contradictions results in the victim losing her case.

According to the existing criminal law, in a rape case, prosecution should prove that the accused had the purported sexual activity with the victim without her ('voluntary') consent (Section 363 of the Penal Code). Independent (expert) thirdparty (forensic) science-based evidence known as medico-legal evidence is extremely important in proving her account at the court of law. It depends on the quality of such evidence. Assessing and maintaining the accuracy of collection and preservation of the evidence and reporting it with scientific analysis to the relevant authorities are of utmost importance in this regard.

The purpose of this study is to analyze the laws pertaining to medico-legal evidence in rape cases. To reach the aforementioned objective the definition, use, purpose and significance of this evidence and medico-legal services available in Sri Lanka will be discussed. A desk review (which includes published journal articles, text books, websites, decided cases and relevant statutes) has been completed to define the key words in this study. Crime statistics pertaining to the offence of rape during the past ten years were analyzed to emphasize the magnitude of the crime. The information gathered from the officials of criminal justice system and field of medicine have also been used to support the objective of the study.

\section{Prevalence of the offence of rape and magnitude of the issue}

The statistics shown in the Table 1 reveal a disturbing trend. Except in 2007 and 2008, the number of reported rape cases reveals that the rate of rape has increased during the last ten years by $30 \%$. This illustrates the vulnerability of women in Sri Lanka for this crime. Nevertheless, some scholars (Edirisinghe A., Wijewardena S., et al , 2014, p. viii ;) are of the view that the dark figure of (rape) rate is higher than the number of reported rape cases to the police. In other words, they are of the view that the actual number of the rape incidents should be higher than the reported cases due to rape survivors not reporting the incidents to the law enforcement authorities (police). Kanagasabapathipillai D., $(2013$, p. 7$)$ states that sexual assaults including rape have increased in the Northern and Eastern provinces since the end of the civil war due to the lack safety and security for women in these areas.

Out of the rape incidents reported to the police, a great number remains unsolved. The figures in table 1 show that a large number of reported rape cases was pending at the (police) investigation stage in each year from 2006 to 2016. In 2006, $77 \%$ of reported cases to the police remained at the investigation stage and it stood at $88 \%$ in 2016 . This shows a $11 \%$ increase in rape cases which were pending at police investigation. In the year 2006, only 369 plaints were filled out of 1540 that were reported to the police. This was only $23 \% .268$ paints were filled out of (2036) total number of the reported cases in 2016 which was $13 \%$ of the total number of the reported cases in that year. It was $10 \%$ decrease. The officials of the law enforcement state that proceedings cannot be instigated due to unnecessary delay in receiving the medicolegal reports and other relevant medical certificates. 
Muthukuda A D S J S Niriella, 2018, European Journal of Social Sciences (EJSS), vol. 1, no. 1,

DOI:10.29198/ejss1802

The statistics of table 1 indicates an increase in the total number of pending (unsolved) cases at different stages such as investigation, preliminary inquiry and trial, from the year 2006 to 2016. For the year 2006, the total number of reported cases was 1540 and the unsolved number of cases stood at 1476 . The percentage of unsolved cases in the year 2006 was approximately 95\%. Out of 2036 cases which have been reported in the year 2016, 2007 cases were pending/unsolved. Statistics confirm that the percentage of unsolved rape cases remained at or above $95 \%$ during the period from 2006 to 2016. Information gathered from the Attorney General's Department endorsed a similar view of the police with regards to the delay in sending case files to the relevant High Courts. Statistics reflecting the negligible number of cases solved .and insignificant number of convictions clearly illustrate the poor quality of response by the criminal justice system.

\begin{tabular}{|c|c|l|l|l|l|c|c|}
\hline Year & $\begin{array}{l}\text { Number } \\
\text { of cases } \\
\text { recorded }\end{array}$ & $\begin{array}{l}\text { Plaints } \\
\text { filed }\end{array}$ & $\begin{array}{l}\text { Investigation } \\
\text { pending }\end{array}$ & $\begin{array}{l}\text { Case } \\
\text { Pending } \\
\text { In MC/ } \\
\text { With AG / } \\
\text { In HC }\end{array}$ & $\begin{array}{l}\text { Total } \\
\text { pending }\end{array}$ & $\begin{array}{l}\text { Ending in } \\
\text { conviction }\end{array}$ & $\begin{array}{l}\text { Ending in } \\
\text { Discharged } \\
\text { or } \\
\text { Acquitted }\end{array}$ \\
\hline 2006 & 1540 & 369 & 830 & 646 & 1476 & 03 & 09 \\
\hline 2007 & 1463 & 295 & 795 & 503 & 1398 & 01 & 06 \\
\hline 2008 & 1397 & 264 & 874 & 482 & 1356 & 03 & 02 \\
\hline 2009 & 1624 & 280 & 1091 & 477 & 1568 & zero & 03 \\
\hline 2010 & 1854 & 167 & 1397 & 397 & 1794 & 03 & 01 \\
\hline 2011 & 1870 & 235 & 1344 & 475 & 1819 & 02 & 02 \\
\hline 2012 & 260 & 44 & 393 & 55 & 248 & Zero & Zero \\
\hline First & 260 & & & & & & 04 \\
\hline 2013 & 2181 & 234 & 1410 & 706 & 2119 & 07 & 04 \\
\hline 2014 & 2008 & 249 & 1159 & 813 & 1972 & 01 & Zero \\
\hline 2015 & 2097 & 239 & 1126 & 641 & 2033 & 01 & 01 \\
\hline 2016 & 2036 & 268 & 1277 & 730 & 2007 & Zero & Zero \\
\hline
\end{tabular}

Statistics in table 2 reveal that during the period from 2006 to 2016, the highest number of rape incidents was recorded in Ratnapura and Anuradhapura. It is also seen that women in rural areas are more vulnerable to rape. Majority of the women in these districts are less educated and unemployed. In many cases, the victim is the sole witness and do not disclose the incident to anybody due to various reasons attributed to the socio-cultural setup in these areas. Often, the first complaint is not lodged immediately after the incident. The incident is not fully disclosed by the victim due to various reasons including social stigma, fear, trauma, anxiety and frustration. This situation is weakening her case against the perpetrator. Furthermore, women who get pregnant as a result of rape are compelled to commit illegal abortion in order to prevent the unwanted pregnancy.

Table 1 Statistics pertaining to the Offence of Rape in Sri Lanka from 2006-2016 CRIME STATISTICS - GRAVE CRIME ABSTRACT FOR THE YEAR - Crime Statistics published by the Department of Police of Sri Lanka 
Muthukuda A D S J S Niriella, 2018, European Journal of Social Sciences (EJSS), vol. 1, no. 1,

DOI:10.29198/ejss1802

\begin{tabular}{|c|c|c|}
\hline Year & $\begin{array}{c}\text { The highest number of Rape } \\
\text { cases reported }\end{array}$ & The District \\
\hline 2006 & 129 & Anuradhapura \\
\hline 2007 & 129 & Anuradhapura \\
\hline 2008 & 102 & Ratnapura \\
\hline 2009 & 131 & Anuradhapura \\
\hline 2010 & 137 & Anuradhapura \\
\hline 2011 & 157 & Ratnapura \\
\hline 2012 & 37 & Ratnapura \\
\hline First quarter & 155 & Ratnapura \\
\hline 2013 & 138 & Ratnapura \\
\hline 2014 & 107 & Ratnapura \\
\hline 2015 & 192 & \\
\hline 2016 & & \\
\hline
\end{tabular}

Table 2: Rape incidents according to the Districts from 2006-2016. Source: Sri Lanka Police Department

\section{Medical Evidence \\ Definition of Medico-Legal Evidence:}

In general terms, medico-legal evidence refers to science based evidence that can be used in a court of law. A similar definition is given in the Law Dictionary (http://dictionary.law.com). More accurately, it refers to documented extra and ano-genital injuries, damages to the emotional state of the victim as well as to the samples and specimens which are taken from the victim's body or clothing for medical tests to submit to the court of law. Such medical records can be used only for legal purposes. This evidence includes saliva, seminal fluid, head hair, pubic hair, blood, urine, DNA, fibre, debris, and soil etc.. (Combrinck H 2003 p.10; Fedkovych H, 2006, p. 9). According to Janice Du Mont and Deborah White (2007 p.9) medico-legal evidence refers to documented proof collected from the victims. This evidence is the best tool in certain circumstances that can be used in court of law to support the case scientifically. Due to the specialized nature of the medico-legal field as a special branch of medical jurisprudence, only medical officers who have been equipped with special knowledge and training can give such evidence in the court of law (Singhal M.L., 1995 p. 86). It is mainly documentary (report /certificate) evidence. In some instances, the relevant medical officers are summoned by the court to testify. Therefore, medico-legal evidence given before the court of law is of two forms, i.e. documentary and oral (http://shodhganga.inflibnet.ac.in/bitstream).

Since this evidence is given by an independent third party who is an expert in the relevant field, medico-legal evidence has great corroborative value. In a rape case, medical opinion could be tendered to establish the mens rea (states of the 
Muthukuda A D S J S Niriella, 2018, European Journal of Social Sciences (EJSS), vol. 1, no. 1,

DOI:10.29198/ejss1802

guilty mind of the accused/criminal intention) that the accused has had at the time of committing the offence.

In Sri Lanka, laws relating to tender the evidence, and the relevancy and admissibility of the evidence in a court case are governed by the Evidence Ordinance No 14 of 1895 . No specific definition is given to the medico-legal evidence in the Law of Evidence in Sri Lanka. Furthermore, medico-legal evidence is not recognized or understood as a distinct form of evidence under the Evidence Ordinance in Sri Lanka. According to section 3 of the Evidence Ordinance called the Interpretation Clause, evidence is defined under the categories of oral evidence and documentary evidence. Therefore, the medico-legal evidence given before a court of law can only be either in oral or documentary form. However, it is important to note that medico-legal evidence can be regarded as an expert opinion under section 45 of the Evidence Ordinance and the relevant medical officers can be summoned before the court to testify when the court is of the view that there is a question regarding any point of science pertaining to the particular (rape) case/ fact in issue.

\section{Significance of Medico-Legal Evidence}

As stated earlier, medico-legal evidence is collected from a victim's body (Ferris LE, Sandercock J.1998 p 349 ; Kelly L, Regan L.2003 p. 10). Therefore, primarily, this evidence can be used to support the investigation and to prosecute the perpetrator (Green W, Panacek EA. 2003 pp 97-99). Consent given by the rape victim is the key fact in establishing the mens reas (the mental element of the crime) in a rape case. Therefore, at the trial, this evidence can be used to prove the inability to consent voluntarily due to uncontrollable influential factors (intoxication insane etc..) resistance made by the woman and the force used by the perpetrator, the facts which are directly relevant to the fact in issue. It can also be used to prove or to exclude the physical connection between the rape victim and the perpetrator, to indicate the connection between the rape victim and the crime scene, to determine the recent occurrence of sexual contact/sexual activity, to identify the perpetrator, to prove penetration/sexual intercourse took place between the woman and the perpetrator, which is important in establishing the actus reus - the physical element of a rape case. In a rape case, it is the strongest evidence that can be used by the prosecution to corroborate the story of the rape victim at the trial in the court of law. However, it is important to note that the same evidence can also be used by the accused to prove his innocence.

Removing the requirement that the physical act (sexual intercourse/access) should be against the woman's will, interpreting the term 'consent' as voluntary consent given by the woman (Sections 363 and 364 of the Penal Code Amendment Act No. 22 of 1995) and removing the need of evidence for actual physical injuries to prove the resistance made by the woman /rape victim (Section 363 Exception 2 of the Penal Code Amendment Act No. 22 of 1995) are some significant changes made to the rape law in Sri Lanka. Prior to 1995, there was a rule of practice which deemed mandatory that independent corroboration to be made to the testimony of a prosecutrix (woman) in a rape case (The King vs Ana Sheriff (1941) NRL 169; The King vs Marthelis (1942) 43 NLR 560; The King vs Themis Singho (1944) 45 NLR 378; The King vs Basnayake (1948) 49 NLR 414 CAA; King vs Athukorala (1948) 50 NLR 256 CCA). The said requirement, that the physical act should be against her will is no longer presented in the current criminal law of Sri Lanka. Currently, evidence for resistance such as physical injuries to body (especially the victim of rape) is not essential to prove that the particular act (sexual intercourse/penetration) took place without her 
Muthukuda A D S J S Niriella, 2018, European Journal of Social Sciences (EJSS), vol. 1, no. 1,

DOI:10.29198/ejss1802

consent. Therefore, it is now established in rape law in Sri Lanka, that it is not essential to corroborate the evidence given by the woman /rape victim (Inoka Galage vs Kamal Addararachchi (2002) 1 SLR 307). However, until to date, in practice, (many) Judges (on several occasions) looked for corroborative evidence to prove the resistance made by the rape victim /woman. Theoretically, one might argue that the effect of medico-legal evidence as a corroborative evidence is not of a considerable level as of today.

In this study, it was found that many defense lawyers (Un-Official Bar) and judicial officers are of the view that it is unsafe to convict the accused on uncorroborated evidence of the prosecutrix. This view can be supported and justified by the judgments pronounced in Nimal Kumara Jayalath vs Republic of Sri Lanka decided in 2009 ( CA 128/06) .and Heen Banda vs AG (C.A.129/2013) decided in 2013. According to them, the degree of corroboration may vary with the circumstances of the case. Both judicial officers and lawyers representing the Official Bar (Attorneys from the Attorney General's Department) are of the view that with the help of the medico-legal evidence, it would be possible to understand and determine whether sexual intercourse took place between the man and the victim. According to prosecutors, medical evidence is vital in the absence of direct oral evidence of eye witnesses (further see section $60(1,2,3)$ of the Evidence Ordinance) and it is the best evidence (section 60 (4) of the Evidence Ordinance) in the event the victim is the sole witness testifying at the trial. However, they agreed upon the fact that this depends on the quality and the reliability of the evidence.

\section{Collecting Medico-Legal Evidence}

The law relating to police investigation of a crime is governed by the law of criminal procedure that set out in the Code of Criminal Procedure Act No
15 of 1979 (Cr.P.C). The relevant provisions for police investigations are set out in Part $\mathrm{V}$, Chapter XI - section 108-125 of the Cr.P.C. In a rape case, the police investigation is initiated after receiving the first information about the incident (Section 109 (1)). The first information can be lodged by the rape survivor (rape victim) or any person on behalf of the victim. During the investigation period, the victim has to interact with the police and other relevant public officials such as the Government Medical Officers as interpreted in section 3 of Cr.P.C. For the purpose of the Act Government medical officer includes any of the Department of Forensic Medicine of any Faculty of medicine of the University of Ceylon (Sri Lanka).

According to section 122 Cr.P.C. it is mandatory for the rape victim to be referred only to a government hospital for medical examination (section 122 Cr.C.P) . Consent of the rape victim is required prior to the referral (section 122 (1)). However, in a situation where the woman does not offer consent for a medical examination, the police may apply to the Magistrate who possesses the jurisdiction within the area the investigation is being conducted, for an order authorizing a Government Medical Officer (GMO) to examine the woman and report there on (Section 122(2) ). In such circumstances the Magistrate is empowered to issue an order authorizing a GMO in order to examine the rape victim who did not consent to being examined (Section 122(2). Therefore, it may say, in a rape case, the victim's consent for medical examination is immaterial or of minor importance. The medical reports showing the results of the examination (and if there is any other medical certificate) should be submitted to the police by the GMO after conducting the medical examination (Section 122 (1). This medical report supports the investigation and prosecution against the accused. It is also important for medico-legal evidence to prove 
Muthukuda A D S J S Niriella, 2018, European Journal of Social Sciences (EJSS), vol. 1, no. 1,

DOI:10.29198/ejss1802

the charge levelled against the accused or to prove his innocence during the trial. Furthermore, the medical examination helps to detect any ailments of the patient, to decide if any further medical attention and treatments are required. However, it is observed that our criminal law is silent with regards to the execution of procedures adopted in conducting medical examinations and /collecting medicolegal evidence.

\section{Medico-Legal services}

According to (Janice Du Mont and Deborah White , 2007 p. 9), as a result of the ongoing weaknesses of criminal justice systems and the lack of quality medico-legal evidence to prove the account of the crime victim, in some countries a service has been established to improve medico-legal responses to criminal cases especially sexual assault cases including rape. This is known as medico-legal services. Under such services medical examinations or medical tests /assessments are carried out by a medico-legal expert for the purpose of preparing a report (medico-legal report) which can be potentially used only for the legal purposes. In general term, medico-legal expert means an independent person who would, if called as witness at a trial of criminal proceedings, be qualified to give opinion as an expert medicolegal witness in relation to a medico-legal issue arising in the proceeding. Generally the medicolegal experts are the medical doctors who have special knowledge and training in Forensic Pathology. And a medico-legal report is a document prepared and submitted by a medicolegal expert with his/her opinion on the issues regarding the proceedings. The institutions that should provide such services, professionals who deliver this services and the procedures that should be followed when providing the services are defer among the countries due to the difference in the health care system from one country to another.
In Sri Lanka neither the Evidence Ordinance nor the Criminal Procedure Code has a specific definition for medico-legal services. According to the Criminal Procedural Law, a rape victim is referred by the police or sometimes by the court to the GMO. Thus, only the government healthcare system which is governed under the Ministry of Health can provide these services. In Sri Lanka, medico-legal services are available from Peripheral Units to all the hospitals such as District Hospitals,. Teaching Hospitals and Tertiary Care Hospitals. The procedural laws in Sri Lanka have not set out provisions pertaining to the procedure of carrying out the medical examinations, preserving the specimens and preparing reports etc.,

A set of guidelines for the examination, reporting and management of sexually abused survivors for medico-legal purposes was introduced in 2014 by the College of Forensic Pathologists of Sri Lanka to improve the quality of the medicolegal services provided and to ensure the uniformity of the service conditions island-wide. (The guidelines are known as 'National for the examination, reporting and management of sexually abused survivors for medico-legal purposes').

For the purpose of the national Guidelines there are three categories of doctors who can carry out medico-legal examination. They are Category One - Board Certified Specialist in Forensic Medicine; Category two- Grade Medical Officers - doctor who has a postgraduate diploma or has been working in the Government Medical Care after internship. And category three - Government Medical Officer- a doctor who has a basic medical degree (MBBS/ or equivalent) registered in the Sri Lanka Medical Council (SLMC) and works for the Government.

In practice, the Judicial Medical Officer (JMO ) who is a medical doctor, full -time specialist 
Muthukuda A D S J S Niriella, 2018, European Journal of Social Sciences (EJSS), vol. 1, no. 1,

DOI:10.29198/ejss1802

consultant in forensic medicine, a branch of medicine/medical field that links medicine with law and the legal process comes under the category of Board Certified Forensic Medicine Specialist for the purpose of National Guidelines. JMO is a state employed servant, accountable to the Ministry of Justice. JMO is specially qualified in forensic pathology with extensive post graduate qualifications with domestic and international training. (Lewis Davis, 2010). For the purpose of the National Guidelines, JMOs belong to the category one. Grade Medical Officer, in practice known as Medical Officer Medico-Legal (MO Medico-Legal) fall under category two. Government registered ordinary doctors belong to category three.

According to the National Guidelines, in a situation where the said doctors come under category one and two are not available in a government health care institution, the doctors belonging to the third category can perform such an investigation and prepare the report. It seems that there is a deference between section 3 of Cr.P.C and National Guidelines on the definition given for Government Medical Officer. One may argue that the National Guidelines do not serve the purpose outlined by the Criminal Procedural Laws. Also it could be argued that the legal validity of a medico-legal report submitted by such medical officer with analysis and onion can be challenge at the trial.

Edirisinghe A (Medico-Legal Journal of Sri Lanka 2011,p. 12) states that there were many areas that requires improvement especially on operational procedures where medical expert input can change many things. This study observed that there is considerable gap between the carder position of JMO and MO Medico-Legal available and the number in-service. In many government health care institutions (especially in rural areas- including Anuradhapura, Ratnapura and North and Eastern) GMOs with basic medical degree have to perform such medical examination. Further, observed that the less interest of the medical doctors to specialize in forensic medicine and in Sri Lanka only a few female medical doctors serve as JMOs and MOMedico Legal. This situation will continue without any changes.

According to the National Guidelines, it is required to be obtained the consent in writing from examinee (a patient who is referred by the police or the court a medico-legal examination). However, such consent is not necessary if the referral is made by the Magistrate. (section 122 (2) of Cr.P.C)

Although the national guidelines define some terminologies such as victim perpetrator, survivors of sexual abuse, health workers, examinee, child, specialist in forensic medicine, grade medical officer and government medical officer, some important terminologies such as medico-legal service, medico-legal evidence and medico-legal report were not described the national guidelines provide the necessary (detailed) guidance on conducting the medicolegal examination, reporting and management of individuals who have been sexually assaulted. It further, guided the doctors who conducted such examination, to ensure some important rights of the individuals such as right to health care, right to human dignity, right to nondiscrimination, right to information and right to for self-determination.

Although, the National Guidelines introduced comprehensive guidance with regards to the procedure adopted in performing the medicolegal examination and preparing the medicolegal report, in many rural parts of the country the guidelines are not implemented effectively. According to law enforcement officers, rape victims are not given priority, if there is no mortal threat to the victims. They have to wait long hours in the hospitals with the police until 
Muthukuda A D S J S Niriella, 2018, European Journal of Social Sciences (EJSS), vol. 1, no. 1,

DOI:10.29198/ejss1802

the victim is taken in for medical examination. This might aggravate her traumatic condition. In Sri Lanka, there is no mandatory time window within which evidence must be collected. However, the guidelines recommend samples collection and perform of examination within 72 hours after the incident of rape took place.

If the victim is a person who is not mentally sound she is referred to a psychiatrist to examine the her memory power, thinking ability, understanding capacity, communication capability to ascertain the nature of the disability and to opine whether that disability affects, giving consent for sexual activity with the perpetrator. The study found that in many instances, the victim patients have to be transferred from lower level medical care institutions to higher level hospitals due to the unavailability of medical resources.

\section{The gap}

The study conducted a field research to understand the gap between the law relating to medico-legal evidence and practice (-the medico-legal services available). One on one interviews were conducted with law enforcement officials, judicial officers and counsels of official and unofficial bar. Furthermore, the information was gathered from the medical officers who serve in rural areas where the rape rate was high from 2010 2016 in relation to the medico-legal services provided by the low level government medial care institutions. Information was also gathered from the medical officers who serve in North and East government health care institution including both low level and high level medical care institutions. In addition to the above said lacuna in law the study found the fowling weakness in medico-legal service available. They are: lack of advanced technical knowledge of medical officers to interact with rape victims who are under post traumatic stress disorder, lack of special skills to handle the sensitive situation like this nature, lack of the knowledge of basic human rights, lack of support and assistance from other medical experts (non forensic medical officers due to non availability) inadequate supporting staff including nurses who have been specially trained in the field as well as those having special skills to interact with rape victims, lack of infrastructure facilities, reluctance to appear in courts for crossexamination, delay transferring the victims to nearest hospital for JMO consultancy, delay in dispatching the samples and specimens obtained from the examinee, (often rape victims), delay in completing the medical examination as well as sending the report to the relevant authorities. These weaknesses in the service have negative effects on the quality, reliability and evidential value of medico-legal evidence.

\section{Conclusion}

According to the Criminal Code Procedure of Sri Lanka, a police officer investigating a crime of alleged sexual abuse is expected to produce the victim as well as the alleged perpetrator to a government medical officer and obtain a report for evidential purposes. The purpose of this legal requirement is to assist in the administration of justice. Medico-legal evidence of substantial quality is vital in proving the case of the victim and the innocence of the accused. The quality of the evidence depends on the medico-legal examination performed on the examinee. Sound theoretical knowledge, skills in medical examination and interpretation backed by scientific reasoning are required for a quality medico-legal report. Medico-legal services available within the medial care system is imperative in this regard. Though there are laws in existence relating to medico-legal evidence along with a set of guidelines applicable for medico-legal services provided, there is gap seen between the law and practice. This gap has a negative effect on the quality of evidence and in 
Muthukuda A D S J S Niriella, 2018, European Journal of Social Sciences (EJSS), vol. 1, no. 1,

DOI:10.29198/ejss1802

effect, the outcome of the case. There is a great necessity to minimize the found lacking and weaknesses to strengthen the services available in order to submit medico-legal evidence with strong evidential value to provide justice to the rape victim.

\section{References}

Combrinck, H. 2003, 'Criminalization of sexual violence in sub-Saharan Africa', Report prepared for the World Health Organization, Geneva.

Crime Statistics published by the Department of Police of Sri Lanka, $<$ https://www.police.lk/index.php/crime-trends>, accessed July 2017.

Edirisinghe, A. 2011, 'A study on medical Experts input in crime scene investigations CSI Is there room for improvement', Medico-Legal Journal of Sri Lanka, vol.1, no. 1.College of Forensic Pathologists of Sri Lanka.

Edirisinghe, A., Wijewardena, S., et, al. 2014, 'National Guidelines on Examination, Reporting and Management of Sexually Abused Survivors for Medico-Legal Purpose', The College of Forensic Pathologists of Sri Lanka, $<$ http://srilanka.unfpa.org/sites/default/files/pubpdf $>$, accessed July 2017.

Fedkovych, H. 2006, 'Criminalization of sexual violence in eastern Europe (Belarus Poland Russia Serbia Ukraine)', Report prepared for the World Health Organization, Geneva.

Ferris, LE. and Sandercock, J. 1998, 'The sensitivity of forensic tests for rape', Medicine and Law, vol.17.

Green, W. and Panacek, EA. 2003, 'Sexual assault forensic examinations in evolution', The Journal of Emergency Medicine, vol. 25.

'Guidelines for medico-legal care for victims of sexual violence GENDER AND WOMEN'S HEALTH FAMILY AND COMMUNITY HEALTH INJURIES AND VIOLENCE PREVENTION, NONCOMMUNICABLE DISEASES AND MENTAL HEALTH', WORLD HEALTH ORGANIZATION GENEWA,

<http:/apps.who.int/iris/bitstream/10665/42788/1/ 924154628x.pdf >, accessed August 2017.

Janice, DM. and White, D. 2007, 'The uses and impacts of medico-legal evidence in sexual assault cases A global review', World Health Organization.
Kanagasabapathipillai, D. 2013, 'Living with Security Marginalization and Sexual Violence against Women in North and East in Sri Lanka', Published by Minority Rights Group International.

Kelly, L. Regan, L. 2003, 'Good practice in medical responses to recently reported rape especially forensic examinations a briefing paper for the Daphne strengthening linkages project', London, Rape Crisis Network Europe.

Lewis, Davis. Intern, Asian Human Rights Commission. 2010, 'Sri Lanka's Judicial Medical Officers their concerns and the torture shortcut', $<$ http//www.janasansadaya.org/page.php?id>, accessed August 2017.

Medicolegal Wikipedia, $<$ https://en.wikipedia.org/wiki/Medicolegal $>$, accessed July 2017.

Singhal, M.L. 1995, 'Medical Evidence and its Use in Trial of Cases', J.T.R.I.U.P. Journal - First Year. vol.1. no.3.

$<$ http://shodhganga.inflibnet.ac.in/bitstream/10603 145287/10/chapter\%20vi.pdf $>$, August 2017.

Sanders, A. 2002, 'Discountenances, the Rights of Victims and the Remedy of Freedom', New Law Journal London, vol. 19.

Decided Cases Sri Lanka

The King vs Ana Sheriff (1941) NRL 169

The King vs Marthelis (1942) 43 NLR 560

The King vs Themis Singho (1944) 45 NLR 378

The King vs Basnayake (1948) 49 NLR 414 CAA

King vs Athukorala (1948) 50 NLR 256 CCA)

Inoka Galage vs Kamal Addararachchi (2002) 1 SLR

307

Nimal Kumara Jayalath vs Republic of Sri Lanka decided in 2009 ( CA 128/06)

Heen Banda vs AG (C.A.129/2013)

Decided cases in India

Ratan Sing vs State of Punjab 19794 SCC 719 